\title{
THE GENETIC CONTROL OF TRISTYLY IN OXALIS SECTION IONOXALIS
}

\author{
STEPHEN G. WELLER \\ Department of Biological Sciences, University of Illinois at Chicago Circle, Chicago, Illinois 60680 \\ Received 26.iv.76
}

\section{SUMMARY}

Progeny ratios from crosses utilising six tristylous species of Oxalis section Ionoxalis indicate that expression of style forms in this section is generally controlled by two loci which are tightly linked. In diploid species one locus controls the expression of the short style form versus non-short, while the second locus controls the expression of the mid and long style forms. The short allele is epistatic to the mid-long locus, where mid is dominant to long. Control of tristyly is similar in polyploid species, although linkage cannot be detected because of chromosome duplication. Fixation or loss of the mid-long locus would allow the remaining short versus non-short locus to segregate equal numbers of shorts and longs, thus providing a genetic basis for control of distyly.

\section{INTRODUGTION}

GeNeTrC investigations of tristylous species have generally shown that expression of style forms is controlled by a two locus system where two alleles are found at each locus. Variations occur in the dominance and linkage relationships between the loci. In Lythrum salicaria (Lythraceae) and some species of Oxalis (Oxalidaceae) the short allele at the short versus non-short locus is epistatic to the mid-long locus (Fisher and Mather, 1943; Fyfe, 1950). The two loci are unlinked in Lythrum, although linkage has been demonstrated for those species of Oxalis which have been investigated. In several species of Oxalis the short allele is recessive (Von Ubisch, 1926; Fyfe, 1956). The genetic control of tristyly in the North American species of Oxalis section Ionoxalis was investigated to determine the dominance and linkage relationships in this section.

\section{MATERIALS AND METHODS}

A crossing programme was established using plants cultivated in greenhouses from field-collected bulbs. Natural populations were extensively sampled to provide adequate material of all style forms. An attempt was made to collect individuals belonging to different clones. Bulbs were planted individually in separate pots. Each individual was designated as Short, Mid or Long to indicate style form, followed by a letter to indicate a particular individual from a given population. In assigning genetic formulae, the letters $S / s$ and $M / m$ were used to designate the dominant and recessive alleles at the short and mid loci respectively. All pollinations were made using fine forceps. The controlled pollination approach resulted in few obvious cases of contamination. Flowers which were not pollinated failed to produce capsules, indicating that the greenhouses were virtually free of potential Oxalis pollinators. Emasculation was unnecessary because selfpollinations revealed an extremely high degree of self-incompatibility. 
Pollinated flowers were individually tagged, and the capsules collected approximately 2 weeks later. Progenies from identical crosses were grown to the flowering stage, and the style forms recorded. The number of progeny grown averaged about 65 for each pair of parental individuals, depending on the availability of flowers for pollination and the number of seeds lost due to explosive dehiscence of capsules.

\section{Results}

Results of crossing programmes for six tristylous species are presented. Five categories of crosses were made utilising individuals from a population of diploid Oxalis magnifica (Rose) Knuth (Weller 746, UC): long $\times$ short, short $\times$ long, long $\times$ mid, mid $\times$ long and mid $\times$ short. When reciprocal crosses were made the results were identical. Two differing distributions of

TABLE 1

Style forms in progeny of crosses, Oxalis magnifica 746, with proposed genotypes of individuals used in crosses

\begin{tabular}{|c|c|c|c|c|}
\hline \multirow{2}{*}{$\begin{array}{c}\text { Cross } \\
\text { (seed parent } \times \text { pollen parent) }\end{array}$} & \multicolumn{3}{|c|}{ Style forms of progeny } & \multirow[b]{2}{*}{$\begin{array}{l}\text { Proposed genotypes of } \\
\text { individuals used in crosses }\end{array}$} \\
\hline & $\mathrm{S}$ & $\mathbf{M}$ & $\mathbf{L}$ & \\
\hline $\mathrm{LA} \times \mathrm{SA}$ & 21 & 26 & 0 & $s m / s m \times S m / s M$ \\
\hline $\mathbf{L A} \times \mathbf{S B}$ & 55 & $2 *$ & 48 & $\mathrm{sm} / \mathrm{sm} \times \mathrm{Sm} / \mathrm{sm}$ \\
\hline $\mathrm{LA} \times \mathrm{SD}$ & 62 & 0 & 42 & $\mathrm{sm} / \mathrm{sm} \times \mathrm{Sm} / \mathrm{sm}$ \\
\hline $\mathrm{LA} \times \mathrm{MC}$ & 0 & 33 & 50 & $s m / s m \times s M / s m$ \\
\hline $\mathrm{LA} \times \mathrm{MB}$ & 0 & 45 & $24 \dagger$ & $\mathrm{sm} / \mathrm{sm} \times \mathrm{sM} / \mathrm{sm}$ \\
\hline $\mathrm{LA} \times \mathrm{MD}$ & 0 & 72 & 0 & $s m / s m \times s M / s M$ \\
\hline$\overline{\mathbf{M A}} \times \mathbf{L A}$ & 0 & 34 & 44 & $s M / s m \times s m / s m$ \\
\hline $\mathbf{M C} \times \mathbf{L A}$ & 0 & 36 & 33 & $s M / s m \times s m / s m$ \\
\hline $\mathbf{M D} \times \mathbf{L A}$ & 0 & 75 & 0 & $s M / s M \times s m / s m$ \\
\hline $\mathrm{MD} \times \mathrm{SD}$ & 38 & 38 & 0 & $s M / s M \times S m / s m$ \\
\hline $\mathrm{SB} \times \mathrm{LA}$ & 49 & $1 *$ & 57 & $\mathrm{Sm} / \mathrm{sm} \times \mathrm{sm} / \mathrm{sm}$ \\
\hline $\mathrm{SA} \times \mathbf{L A}$ & 53 & $34 \uparrow$ & 0 & $\mathrm{~S} m / s M \times s m / s m$ \\
\hline
\end{tabular}

progeny resulted from short $\times$ long and long $\times$ short crosses, one (from Short B and Short D, table 1) where shorts and longs were produced in equal numbers, and a second (from Short A) where shorts and mids were produced in equal numbers (table 1 ). Mid $\times$ long and long $\times$ mid crosses also produced two differing distributions of progeny. Mids and longs were produced in equal numbers when Mid A, Mid B and Mid C were crossed to longs, while Mid D produced only mids when crossed to longs. Crosses between Short D and Mid D yielded shorts and mids in equal frequency. Deviations from simple ratios occurred in two cases (table 1). A total of three mids appeared in the progeny of Long $\mathrm{A} \times$ Short $\mathrm{B}$ and the reciprocal cross, which represent the effects of contamination or rare cross-overs.

Crosses using representatives of a diploid population of Oxalis lasiandra Zucc. (Weller 753, UC) yielded similar results with short $\times$ long crosses producing either a $1: 1$ ratio of shorts and longs, or a $1: 1$ ratio of shorts and mids (table 2). Mid $\times$ long crosses generally produced equal numbers of mids and longs in the progeny. The proportion of style forms fit simple 
TABLE 2

Style forms in progeny of crosses of Oxalis lasiandra 753, with proposed genotypes of individuals used in crosses

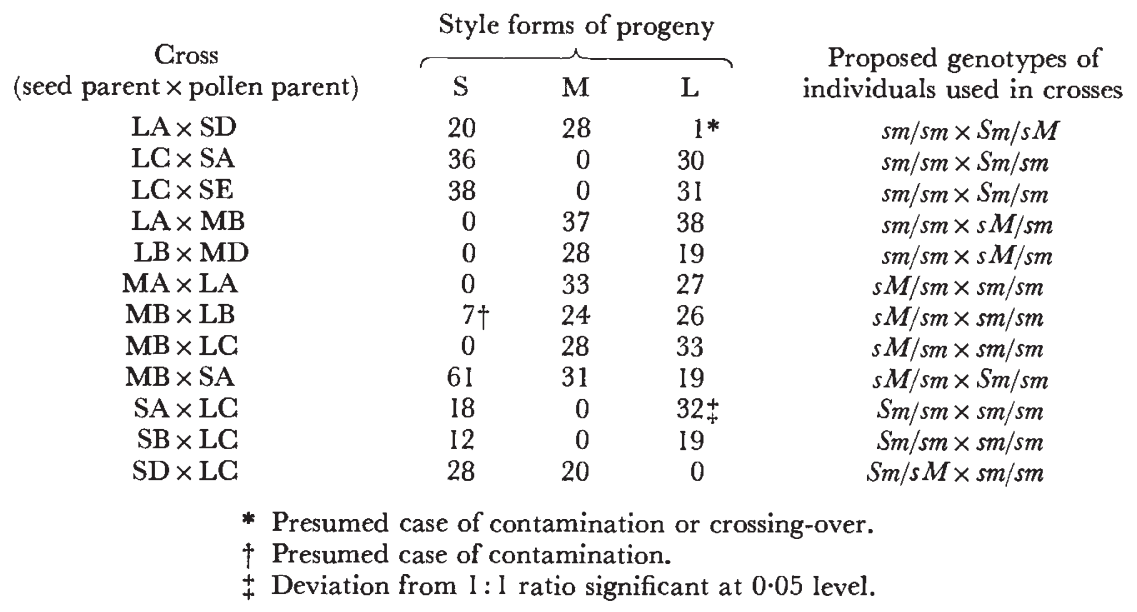

ratios in most cases, although a statistically significant excess of longs was found in the progeny of the Short $A \times$ Long $C$ cross. The cause of this excess is unknown. A few shorts produced by Mid B $\times$ Long $\mathrm{B}$ undoubtedly resulted from contamination, since $\mathrm{Mid} \mathrm{B}$ in other crosses produced no shorts.

Ratios of style forms occurring in the progeny of two other diploid tristylous taxa (table 3 ) are consistent with those obtained for Oxalis magnifica and $O$. lasiandra. The brief flowering period of $O$. macrocarpa (Small) Knuth and the small flowers of $O$. lunulata Zucc. precluded more extensive crossing programmes using these species.

TABLE 3

Style forms in progeny of crosses of Oxalis lunulata 762 and Oxalis macrocarpa 676, with proposed genotypes of individuals used in crosses

\section{Cross}

(seed parent $\times$ pollen parent)

Oxalis lunulata:

$$
\begin{aligned}
& \mathrm{LA} \times \mathrm{SA} \\
& \mathrm{LA} \times \mathrm{MA}
\end{aligned}
$$

Oxalis macrocarpa:

$$
\mathrm{SD} \times \mathrm{LB}
$$

\section{Style forms of progeny}

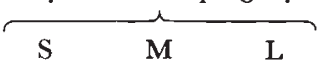

42

0

$0 \quad 41$

$29 \quad 36$

Proposed genotypes of individuals used in crosses

Crossing results were generally consistent between two octoploid populations of Oxalis tetraphylla Cav. var. tetraphylla. A short from one population (Breedlove 15799, CAS) was unusual in producing a 2:1:1 ratio of shorts, mids and longs when crossed with longs (Short A, table 4).

A limited number of progeny were obtained from crosses of representatives of several tetraploid populations of tristylous Oxalis alpina (Rose) Knuth

$37 / 3-F$ 
TABLE 4

Style forms in progeny of crosses of two populations of Oxalis tetraphylla, with proposed segregations and genotypes of individuals used in crosses

\begin{tabular}{|c|c|c|c|c|c|}
\hline \multirow{2}{*}{$\begin{array}{c}\text { Cross } \\
(\text { seed parent } \times \text { pollen parent })\end{array}$} & \multicolumn{3}{|c|}{ Style forms of progeny } & \multirow{2}{*}{$\begin{array}{l}\text { Proposed } \\
\text { segregation }\end{array}$} & \multirow{2}{*}{$\begin{array}{l}\text { Proposed genotypes of } \\
\text { individuals used in crosses }\end{array}$} \\
\hline & $\mathrm{S}$ & $\mathbf{M}$ & $\mathrm{L}$ & & \\
\hline $\begin{array}{l}\text { Population 15799: } \\
\qquad \mathrm{MA} \times \mathrm{SA}\end{array}$ & 28 & 28 & 0 & $1: 1: 0$ & $s_{8} M_{3} m_{5} \times S_{1} s_{7} M_{1} m_{7} *$ \\
\hline $\mathrm{SB} \times \mathrm{LD}$ & 13 & 0 & 11 & $1: 0: 1$ & $S_{1} s_{7} m_{8} \times s_{8} m_{8}$ \\
\hline $\mathrm{LD} \times \mathrm{SB}$ & 51 & 0 & 42 & $1: 0: 1$ & $s_{8} m_{8} \times S_{1} s_{7} m_{8}$ \\
\hline $\mathrm{LD} \times \mathrm{SA}$ & 35 & 20 & 15 & $2: 1: 1$ & $s_{8} m_{8} \times S_{1} s_{7} M_{1} m_{7}$ \\
\hline $\mathrm{LA} \times \mathrm{SA}$ & 13 & 6 & 8 & $2: 1: 1$ & $s_{8} m_{8} \times S_{1} s_{7} M_{1} m_{7}$ \\
\hline $\mathrm{LB} \times \mathrm{MA}$ & 0 & 11 & 1 & $0: 5: 1$ & $s_{8} m_{8} \times s_{8} M_{3} m_{5}$ \\
\hline \multicolumn{6}{|l|}{ Population 593: } \\
\hline $\mathrm{LA} \times \mathrm{SA}$ & 15 & 0 & 24 & $1: 0: 1$ & $s_{8} m_{8} \times S_{1} s_{7} m_{8}$ \\
\hline $\mathrm{LB} \times \mathrm{SA}$ & 44 & 0 & $62 \uparrow$ & $1: 0: 1$ & $s_{8} m_{8} \times S_{1} s_{7} m_{8}$ \\
\hline $\mathrm{LC} \times \mathrm{SB}$ & 19 & 0 & 23 & $1: 0: 1$ & $s_{8} m_{8} \times S_{1} s_{7} m_{8}$ \\
\hline
\end{tabular}

from south-eastern Arizona (table 5). Mid $\times$ long crosses produced either all mids, or equal numbers of mids and longs. One short produced equal numbers of shorts and longs when crossed to longs.

\section{Discussion}

A genetic mechanism for the control of style form inheritance in a tristylous species was first proposed by G. von Ubisch (1921). The proposed model consisted of a two-locus system with two alleles at each locus, with one locus controlling the expression of short versus non-short (the $S / s$ locus) and the second locus controlling the expression of mid versus long (the $M / m$ locus). The short allele was found to be epistatic to the mid-long locus, so that the genotypes $S_{s m m}, S_{s} M m$ and $S_{s} M M$ were phenotypically short, while $s s M m$ and $s s M M$ were phenotypically mid. The double recessive,

TABLE 5

Style forms in progeny of crosses within three populations of tristylous Oxalis alpina, with proposed genotypes of individuals used in crosses

\section{Cross}

(seed parent $\times$ pollen parent)

Chiricahua Mts. (727):

$$
\mathrm{MA} \times \text { long* }
$$$$
\mathrm{SA} \times \text { long* }
$$

White Mts. (713):
Style forms of progeny

$\overbrace{\mathrm{S} \quad \mathrm{L}} \overbrace{\mathrm{L}}$

0

0

$\begin{array}{rr}12 & 15 \\ 0 & 43\end{array}$
Proposed genotypes of individuals used in crosses

ssss $M m m m \times s s s m m m m$ Ssssmmmm $\times$ ssss $\mathrm{mmmm}$

ssssmmmm $\times$ ssss $M m m m$

Huachuca Mts. (702): $\mathrm{MA} \times \mathrm{LA}$ 
$s s m m$, was phenotypically long. Von Ubisch based this scheme on data collected by Barlow (1913). The progeny ratios found in species of section Ionoxalis conform in many respects to this genetic model. All crosses in section Ionoxalis involving a short parent produced progeny containing shorts and non-shorts in a $1: 1$ ratio, verifying that the short parents were uniformly heterozygous. Heterozygosity at the short versus non-short locus of individuals with the short phenotype shows that the $S$ allele is dominant, because in a self-incompatible species homozygosity of the $S$ allele would be expected only if the allele were recessive, and could be masked by the presence of another allele. The appearance of mids in the progeny of several crosses between short and long individuals (746-Long $\mathrm{A} \times$ Short $\mathrm{A}, 753$ Long $\mathrm{A} \times$ Short $\mathrm{D}$ and Short $\mathrm{D} \times$ Long $\mathrm{G}$, and 676-Short $\mathrm{D} \times$ Long $\mathrm{B}$ ) indicates that the $S$ allele is epistatic to the $M$ allele. The appearance of only mids in the progenies of the 746-Mid $\mathrm{D} \times$ Long A and reciprocal crosses indicates that the $M$ allele is dominant to $m$ and that the mid parent was homozygous for the $M$ allele. Thus, crossing results allow a short-mid-long sequence of dominance to be established.

Linkage between the short and mid loci is probable in section Ionoxalis. Without linkage, diploid shorts containing a single $M$ allele would produce shorts, mids, and longs in a 2:1:1 ratio when crossed to longs. Diploid shorts containing two mid alleles would produce only shorts and mids in a $1: 1$ ratio. When the two loci are linked, different ratios result, depending on whether the alleles are linked in repulsion or coupling. A short with an $M$ allele linked in repulsion $(S m / s M)$ would produce only mids and shorts in the progeny when crossed to a long $(\mathrm{sm} / \mathrm{sm})$, assuming that no crossing-over occurred. A short with one $M$ allele linked in coupling $(S M / s m)$ would produce only shorts and longs when crossed with a long, again assuming that no crossing-over occurred. Thus, in the case of linkage, 2:1:1 ratios would not occur in the progeny of a short $\times$ long cross of a diploid species. In crosses of shorts and longs of diploid species of section Ionoxalis, no 2:1:1 ratios were found. Of the nine shorts used in genetic crosses, the six shorts producing no mids in their progeny could either have the $S M / \mathrm{sm}$ or $\mathrm{Sm} / \mathrm{sm}$ genotype. The three shorts producing mids in their progeny following matings with longs would most likely have the $S \mathrm{~m} / \mathrm{s} M$ genotype, although a few short individuals would be expected to carry two doses of the $M$ allele (Fisher, 1941).

Two examples of a 2:1:1 ratio in the progeny of short $\times$ long mating occurred in crosses of Oxalis tetraphylla (Breedlove 15799, CAS) (table 4). This ratio probably resulted from the presence of the $M$ allele on a chromosome which did not pair with the chromosome carrying the dominant $S$ allele. Mid $(M)$ and $S$ alleles would appear to be segregating independently due to the effects of chromosome duplication. Assignment of genotypes to polyploid individuals is difficult since the simple segregation ratios of diploid species become more complex as the ploidal level increases. Very large numbers of progeny would be necessary to unequivocally assign genotypes to polyploid individuals.

Control of style form inheritance is generally similar in Oxalis valdiviensis (section Laxae) and section Ionoxalis. In her initial studies of $O$. valdiviensis, Barlow (1913) did not realise that the two loci were linked, and was unable to develop a scheme for the genetic control of tristyly in this species. Fyfe (1950) suggested that the two loci were linked, and estimated recombination 
at $5 \cdot 74$ per cent. Recombination cannot be unequivocally demonstrated in section Ionoxalis, since the few individuals which could be interpreted as the products of crossing-over could have resulted from contamination. Mid alleles could be linked in coupling to the short allele of the short individuals which are assigned genetic formulae in tables 1-5. The only major difference between inheritance of tristyly in section Laxae and section Ionoxalis is the complication of polysomic inheritance in some species of section Ionoxalis. The genetic system controlling expression of style forms in tristylous taxa of Oxalis section Corniculatae is also similar to the system found in section Ionoxalis, although there is no evidence for linkage (Ornduff, 1972). As a result of the self-compatibility which is common in section Corniculatae, homozygous short genotypes are occasionally encountered. Self-pollinations revealed that a short-mid-long sequence of dominance is also found in section Corniculatae (Ornduff, 1972).

More significant differences are found in the control of tristyly in Oxalis rosea, where von Ubisch (1926) demonstrated that the short allele was recessive. Fyfe (1956) found the same dominance relationship in $O$. articu$l a t a$, although these names may refer to the same taxon. Control of style form expression in polyploid races of Lythrum salicaria (Lythraceae) is similar to the system found in the polyploid species of section Ionoxalis (Fisher, 1941; Fisher and Mather, 1943). Genetic control of tristyly in the Pontederiaceae, the third family in which tristyly has been reported, has not been extensively studied. Only a few species in the Pontederiaceae appear to have demonstrably tristylous breeding systems (Ornduff, 1966).

Control of tristyly in section Ionoxalis appears to be similar in the species used in this study, including trimorphic populations of Oxalis alpina where distylous incompatibility relationships have evolved (Weller, 1976). Several other lines of evidence suggest that distyly is derived from tristyly in section Ionoxalis (Weller and Denton, 1976). Fixation or loss of the mid-long locus in section Ionoxalis would easily provide the genetic basis for control of distyly, since the remaining short versus non-short locus would allow segregation of equal numbers of short and long progeny. Because of the epistatic nature of the $S$ allele, loss of the mid style form would be gradual, as matings between shorts carrying the $M$ allele and longs continue to expose the $M$ allele to the action of selection.

Acknowledgments. - I wish to thank Robert Ornduff for his advice throughout the course of this study, which is based on a thesis submitted to the Graduate Division, University of California, Berkeley, in partial fulfilment of the requirements of the degree of Doctor of Philosophy. I also thank Melinda F. Denton for reading an earlier version of this paper.

\section{References}

BARLOW, N. 1913. Preliminary notes on heterostylism in Oxalis and Lythrum. 7. Genet., 3, 53-65.

FISHER, R. A. 1941. The theoretical consequences of polyploid inheritance for the mid form of Lythrum salicaria. Annals of Eugenics, 11, 31-38.

Fisher, R. A., AND MATHER, K. 1943. The inheritance of style lengths in Lythrum salicaria. Annals of Eugenics, 12, 1-23.

FYFE, V. C. 1950. The genetics of tristyly in Oxalis valdiviensis. Heredity, 4, 365-371.

FYFE, v. c. 1956. Two modes of inheritance of the short-styled form in the "genus" Oxalis. Nature, 177, 942-943. 
ORNDUfF, R. 1966. The breeding system of Pontederia cordata L. Bull. Torrey Bot. Club, 93, 407-416.

ORNDUFF, R. 1972. The breakdown of trimorphic incompatibility in Oxalis section Corniculatae. Evolution, 26, 52-65.

voN UBisch, G. 1921. Zur Genetic der trimorphen Heterostylie sowie einige Bemerkungen zur dimorphen Heterostylie. Biol. Zentralbl, 41, 88-96.

voN ubisch, G. 1926. Koppelung von Farbe und Heterostylie bei Oxalis rosea. Biol. Zentralbl., 46, 633-645.

WELLER, s. G. 1976. Breeding system polymorphism in a heterostylous species. Evolution (in press).

WELlER, S. G., AND DENTON, M. F. 1976. Cytogeographic evidence for the evolution of distyly from tristyly in the North American species of Oxalis section Ionoxalis. Am. 7 . Bot., 63, 120-125. 